\title{
Relationship Between Critical Thinking and Compensatory Strategies by Iranian Upper-Intermediate EFL Learners in Oral Communication
}

\author{
Mahmood Hashemian \\ Shahrekord University; m72h@hotmail.com \\ Azizullah Mirzaei \\ Shahrekord University; mirzaei-a@lit.sku.ac.ir \\ Masoomeh Abaszadeh \\ Shahrekord University; masumeabaszade@gmail.com
}

\section{Doi:10.5901/mjss.2015.v6n6s1p11}

\section{Abstract}

\begin{abstract}
Critical thinking (CT) is defined by American Philosophical Association as purposeful, self-regulatory judgment that results in interpretation, analysis, evaluation, and inference and is founded on conceptual criteria upon which a judgment is based (Facione \& Facione, 1996). Compensatory strategies are compensation for missing knowledge. The present study aimed at investigating the (possible) relationship between Iranian upper-intermediate EFL learners' CT and their compensatory strategies, such as circumlocution and approximation. To achieve this goal, $40 \mathrm{EFL}$ learners majoring in English translation in Shahrekord University, Iran were selected and homogenized in terms of proficiency. Then, the sample was asked to take the Watson-Glaser Critical Thinking Appraisal (CTA) and to complete a researcher-designed questionnaire about their preferred types of compensatory strategies. Spearman correlation method was used to analyze the data. Results indicated that there is a positive correlation between CT and some compensatory strategies like appeal for help and nonlinguistic signals. Findings may help $L 2$ teachers to have a better and realistic view towards L2 learners' choice of compensatory strategies. Besides, results may also help L2 learners to have more awareness of compensatory strategies and their own CT. Therefore, this awareness can lead them to an effective $L 2$ education.
\end{abstract}

Keywords: Critical Thinking (CT), Compensatory Strategies, Approximation, Circumlocution

\section{Introduction}

Everyone thinks; this is our nature to do so, but mere thinking does not necessarily guarantee critical thinking (CT). Actually, much of our thinking is biased, distorted, or prejudiced. Halpern (1998) argues that CT is purposeful, reasoned, and goal-oriented. It is the kind of thinking involved in solving problems, formulating inferences, calculating likelihoods, and making decisions.

As Freely and Steinberg (2000) state, CT is "the ability to analyze, criticize, and advocate ideas; to reason inductively and deductively; and to reach factual or judgmental conclusions based on sound inferences drawn from unambiguous statements of knowledge or belief" (p. 2). Moon (2008) believes that CT can be influential in higher education and professions. Definitely, it plays a key role in education and academic objectives due to its association with problem-solving and decision-making. Dewey (1993) stated that the central purpose of education is learning to think. The prerequisite for L2 learners to have a successful higher education is being able to think critically. It is worth mentioning that CT is not a congenital ability; on the other hand, it is an ability that must be achieved through practice.

Regarding compensatory strategies, we need to have a brief explanation about the nature of communication. According to Lynch (1996, p. 3), "communication involves enabling someone else to understand what we want to tell them, what is often referred to as our message." In order to reach a communicative goal, the speaker or the message sender has the responsibility to make the message comprehensible and clear. There are many communication strategies employed by message sender (or even message receiver) to make the intended message understandable (e.g., L2 learners may not know the word ferry and they may use the word ship instead; actually, they employ the approximation strategy). 
Tarone (1983) defines communication strategies as "a mutual attempt of two interlocutors to agree on a meaning in situation where requisite structures do not seem to be shared" (p. 65). Faerch and Kasper (1983) define communication strategies as "potentially conscious plans for solving what to an individual presents itself as a problem in reaching a particular communicative goal" (p. 36). They argue that there are two different types of communication strategies: reduction (or avoidance) and achievement strategies.

Corder (1983) characterizes reduction strategies as "risk avoiding" and achievement strategies as "risk taking" (p. 15). Faerch and Kasper (1983) divide achievement strategies into compensatory strategies and retrieval strategies. Compensatory strategies are employed whenever L2 learners want to compensate their insufficient linguistic resources in communication. According to Faerch and Kasper (1983), compensatory strategies can be divided into noncooperative and cooperative strategies. When L2 learners try to solve their problems by themselves, without any appeal for help from others, actually they are employing noncooperative strategies. On the other hand, when they try to solve their problems by direct or indirect appeals, they are employing cooperative strategies.

\section{Literature Review}

CT has been the concern of many studies (e.g., Barjesteh \& Vaseghi, 2012; Nikoopour, Amini Farsani, \& Nasiri, 2011). Due to its important role in different areas, specifically in educational matters, CT has been interesting for investigators. A glance at the literature review of CT shows that it is an inseparable part of studies concerning the successful achievement in education, learning strategies, and reading strategies.

Nour Mohammadi, Heidari, and Dehghan Niri (2012) investigated the relation between CT ability and reading strategies used by Iranian EFL learners. They asked 75 Iranian EFL learners (35 males and 40 females) majoring in English literature and English translation at the University of Sistan and Baluchestan to participate in their study. The participants were asked to take a CT questionnaire and a reading strategy questionnaire. The researchers found that the most frequently used reading strategy was metacognitive strategy. Statistical analysis showed that there was a low positive significant correlation between the participants' CT ability and their overall use of reading strategies. In addition, the participants' CT ability correlated positively with their use of each one of cognitive, metacognitive, and compensation strategies.

Other researchers tried to find out the relation between CT and language learning strategies among Iranian EFL learners (Nikoopour, Amini Farsani, \& Nasiri, 2011). In the study by Nikoopour, Amini Farsani, and Nasiri (2011), 100 college students majoring in English translation at Azad University of Karaj were asked to complete the Strategy Inventory for Language Learning (SILL) and a questionnaire concerning CT. The findings revealed a statistically significant relationship between specific direct and indirect language learning strategies such as cognitive, metacognitive, and social with CT; on the other hand, memory, compensation, affective strategies appeared to have no relationship with CT.

In addition, Barjesteh and Vaseghi (2012) tried to probe the role of CT skills on Iranian EFL learners' reading comprehension performance. To attain the goal of the study, 240 female and male Iranian EFL learners were selected and screened into two proficiency levels, and then each proficiency level was divided into critical and noncritical groups. The findings showed that CT skills significantly affected the EFL learners' reading comprehension performance. Also, the findings provided empirical support for the facilitative effect of CT strategy training on the reading comprehension performance of EFL learners.

Literature is also rich in terms of studies about compensatory strategies. In his study about the use of compensatory strategies in L2 learners' interlanguage, ČurkovićKalebić (2007) concluded that compensatory strategies are not equally distributed in L2learners'interlanguage. Some of the strategies like code-switching, paraphrase, and literal translation were very frequent. However, strategies like generalization and word coinage were not that much present. He also concluded that the use of compensatory strategies and their type is affected by L2learners' level of proficiency. For example, upper-intermediate learners show tendency to use more L2-based strategies, rather than L1-based ones. In other words, he believes that L2 learners' proficiency level might be one of the factors upon which the choice of compensatory strategies depends.

\section{Statement of the Problem}

EFL teaching and learning has undergone big changes. A shift has occurred from viewing learning primarily as rote training to conceptualizing learning as a constantly evolving process of discovering, questioning, and reformulating hypotheses (Penny Cook, 1994). However, according to Paul (1987), in most educational systems, much of L2 learning 
is gained through rote memorization that results in misunderstanding, prejudice, and discouragement, so it blocks L2 learners' CT ability. Unfortunately, the Iranian educational system does not focus on CT in L2 learning. Usually, L2 learners' views and ideas are disregarded, and they are not given any chance to express themselves.

As part of education, L2 learners need to develop and learn to apply CT skills to their academic studies effectively (Kealey, Holland, \& Watson, 2005), to the complex problems that they face in their professions (Yeh, 2004), and to the critical choices they will be forced to make as a result of the information explosion and other technological changes (Oliver \& Utermohlen, 1995).

CT has been in center of attention for a long time. Its importance in education is due to its relevance to problemsolving and decision-making. Many researchers (e.g., Ghanizadeh \& Moafian, 2011; Nikoopour, Amini Farsani, \& Nasiri, 2011) have investigated different aspects/impacts of CT in L2 learning contexts. To our belittled knowledge, there is a gap in the literature about the (possible) relationship between CT and compensatory strategies employed by Iranian EFL learners.

In line with the aforementioned discussion and for the purpose of this study, the following questions have been formulated to be addressed:

1. Is there any significant difference between $\mathrm{L} 2$ learners' gender and their CT ability?

2. Is there any significant relationship between CT and the types of compensatory strategies among intermediate and upper-intermediate L2 learners?

3. Is there any significant difference in preference of compensatory strategies among intermediate and upperintermediate L2 learners?

4. Is there any significant relationship between subcategories of CT and each compensatory strategy among intermediate and upper-intermediate L2 learners?

\section{Methodology}

\subsection{Participants}

For the purpose of the study, 40 junior and senior students (15 males and 25 females), aged 21-30, majoring at English translation in Shahrekord University, Iran were randomly selected. From among the sample, 10 were asked to take part in piloting process.

\subsection{Materials}

To gather the data, three instruments namely, the Oxford Placement Test (OPT; Allen, 2009), Watson-Glaser Critical Thinking Appraisal (CTA) (2002), and a researcher-designed questionnaire about preferred types of compensatory strategies were employed. The participants were asked to fill out all the two questionnaires.

\subsection{Procedure}

In order to homogenize the participants in terms of language proficiency and to avoid any other intervening factor, the OPT was conducted. After running the OPT, the participants at intermediate and upper-intermediate levels were given the other two instruments.

To test their CT ability, the researchers utilized Watson-Glaser CTA. As noted before, this test is one of the highly standardized and frequently used CT tests employed by many researchers (e.g., Barjesteh \& Vaseghi, 2012; Nikoopour, Amini Farsani, \& Nasiri, 2011) in their studies. As far as the reliability is a sample-based phenomenon, it was calculated through Cronbach's alpha and it was found to be .85 . The third instrument was a researcher-designed questionnaire that aimed at evaluating preferred types of compensatory strategies adopted by Iranian EFL learners.

The researchers designed a questionnaire that tested five compensatory strategies. The questionnaire was based on a 5-point Likert-scale ranging from 1 (Strongly Agree) to 5 (Strongly Disagree). The aforementioned questionnaire was made up of five parts, each of which contained six questions. The respondents were provided with some situations in which they were supposed to think as if they were speaking with their friends in English class while their L1 is Farsi and the conversation was happening under the surveillance of an EFL teacher. The researchers tested five compensatory strategies: circumlocution, approximation, code-switching, appeal for help, and nonlinguistic signals through the five parts accordingly. The reliability of this test was also calculated via Cronbach's alpha, and the estimate turned out to be .75 . The validity was also calculated through Kaiser-Mayer-Oklin value, and it was found to be .71 . 


\section{Results}

\subsection{Descriptive Statistics of CT and Compensatory Strategies}

In order to have a general description of the data, descriptive statistics (i.e., mean, minimum, maximum scores, standard deviations, Skewness, and kurtosis) were calculated for the two questionnaires used in the study. As mentioned before in chapter 3, the Watson-Glaser CTA included 80 items through five subsections. In addition, the questionnaire about the compensatory strategies had 30 items within five sections. It is noteworthy that after calculating the CT scores based on Watson-Glaser CTA classification, the participants were divided into three groups: (1) participants who scored 35 and below formed the low critical-thinking group, (2) those scoring between 36-55 were placed in mid critical-thinking group, and (3) those who got between 56-80 were classified into high critical-thinking group.

As the results indicated, the mean score of the high critical-thinking group ranged from 1 to 10.50 for the different subcategories of compensatory strategies. In addition, for the mid critical-thinking group the mean scores ranged from 2 to 11.17. Finally, the mean score of low critical-thinking ranged from 3 to 14.17. The minimum and maximum score for each type of compensatory strategies for the high, mid, and low critical-thinking groups were respectively reported to be 6-25, 6-30, and 6-24.

Based on the obtained mean scores, the priority of compensatory strategies for both the high and mid criticalthinking groups was code-switching. Moreover, nonlinguistic signals were prioritized by the low critical-thinking group.

Table 1 shows the comparison of the males and females in CT ability. According to Table 1, the obtained mean for males (2.17) was higher in comparison with their female counterparts (1.96). This shows that the males outperformed the females on CT ability.

Table 1. Mean Scores of Male and Female Participants

\begin{tabular}{ccc}
\hline Groups & Mean & Std. deviation \\
\hline Males & 2.14 & .69 \\
\hline Females & 1.96 & .63 \\
\hline
\end{tabular}

To compare these two means, $t$ test was applied. Based on Table 2, the $t$ test value (Sig. $=.66$ ) revealed that there was not a statistically significant difference between the males and females. Therefore, we cannot assume that males are better critical thinkers:

Table 2. $t$ Test Results of Males and Females

\begin{tabular}{cc}
\hline$t$ & $d f$ \\
\hline .66 & 28 \\
\hline *Statistically significant $(p<.05)$ &
\end{tabular}

\subsection{Results of Correlation Between Overall CT Ability and Compensatory Strategies}

In order to find out the potential relationship between the overall CT ability and the five compensatory strategies, Spearman correlation was run. Table 3 displays the correlation between the high, mid, and low critical-thinking groups and the preferred type of compensatory strategies. According to Table 3, there was a positive and significant correlation between the mid critical-thinking group and appeal for help as a compensatory strategy. In addition, there was a positive and significant correlation between the low critical-thinking group and nonlinguistic signals as a compensatory strategy: 
Table 3. Correlation Between Overall CT Ability and Compensatory Strategies

\begin{tabular}{cllcc}
\hline CT & Types of Compensatory Strategies & Spearman's Rho & Sig. (2-tailed) \\
\hline High & Circumlocution & 1.00 &. \\
\cline { 2 - 4 } & Approximation & .75 & .08 \\
\cline { 2 - 4 } & Code-Switching & .49 & .32 \\
\cline { 2 - 4 } & Nonlinguistic Signals & .08 & .86 \\
\cline { 2 - 4 } & Appeal for Help & .26 & .61 \\
\hline \multirow{2}{*}{ Mid } & Circumlocution & 1.00 & .28 \\
\cline { 2 - 4 } & Approximation & .26 & .87 \\
\cline { 2 - 4 } & Code-Switching & .03 & .30 \\
\cline { 2 - 4 } & Nonlinguistic Signals & .25 & .02 \\
\cline { 2 - 4 } & Appeal for Help & .34 & .16 \\
\hline \multirow{2}{*}{ Low } & Circumlocution & 1.00 & .95 \\
\cline { 2 - 4 } & Approximation & .64 & .01 \\
\cline { 2 - 4 } & Code-Switching & .03 & .51 \\
\cline { 2 - 4 } & Nonlinguistic Signals & .89 & .33 & .39 \\
\cline { 2 - 4 } & Appeal for Help & & \\
\hline
\end{tabular}

Note. $p<.05$ (2-tailed)

Simply speaking, it can be deduced that the participants with low CT ability used nonlinguistic strategy more than other strategies. Moreover, the mid critical-thinking group utilized appeal for help strategy more.

In order to find the participants' preference in terms of use of compensatory strategy, a series of chi-square tests were run to find out the most significant compensatory strategies in different CT levels. The results are shown in Table 4. As the results indicate, the chi-square tests achieved significant results for "appeal for help" as a compensatory strategy in the mid critical-thinking group. Due to the results, "appeal for help" is the most preferred type of compensatory strategies for the mid critical-thinking group. According to the results, there is no significant difference regarding the preference of other four compensatory strategies among the high, mid, and low critical-thinking groups.

Table 4. Chi-Square Results for the Preferred Type of Compensatory Strategies

\begin{tabular}{lll}
\hline CT & Types of Compensatory Strategies & Sig. \\
\hline High & Circumlocution & .95 \\
\cline { 2 - 3 } & Approximation & 1 \\
\cline { 2 - 3 } & Code-switching & \multicolumn{1}{c}{1} \\
\cline { 2 - 3 } & Appeal for Help & .95 \\
\cline { 2 - 3 } & Nonlinguistic Signals & .95 \\
\hline Mid & Circumlocution & .64 \\
\cline { 2 - 3 } & Approximation & .54 \\
\cline { 2 - 3 } & Code-switching & .94 \\
\cline { 2 - 3 } & Appeal for Help & $.05^{\star}$ \\
\cline { 2 - 3 } & Nonlinguistic Signals & .98 \\
\hline Low & Circumlocution & .57 \\
\cline { 2 - 3 } & Approximation & .95 \\
\cline { 2 - 3 } & Code-switching & .57 \\
\cline { 2 - 3 } & Appeal for Help & .22 \\
\cline { 2 - 3 } & Nonlinguistic Signals & \\
\hline Note. ${ }^{*}<<.05$ & (2-tailed) &
\end{tabular}

In order to find out the correlation between subcategories of CT and each strategy, Pearson's product-moment correlation was employed. As shown in Table 5, a positive and significant correlation was found between "deduction" and "nonlinguistic signals." It can be deduced that the higher ability of deduction led to more use of nonlinguistic signals. 
Moreover, in terms of "evaluation of arguments," a positive and significant correlation was found between "evaluation of arguments" and "nonlinguistic signals." It shows that the higher ability in evaluation of arguments led to more use of nonlinguistic signals (see Table 5):

Table 5. Correlation Between Subcategories of CT and Compensatory Strategies

\begin{tabular}{|c|c|c|c|}
\hline CT Components & Types of Compensatory Strategies & Correlation Coefficient & Sig. (2-tailed) \\
\hline \multirow[t]{5}{*}{ Inference } & Circumlocution & .20 & .26 \\
\hline & Approximation & -.51 & .09 \\
\hline & Code-switching & -.17 & .35 \\
\hline & Nonlinguistic Signals & .26 & .15 \\
\hline & Appeal for Help & -.14 & .43 \\
\hline \multirow[t]{5}{*}{ Recognition of Assumption } & Circumlocution & .12 & .49 \\
\hline & Approximation & .00 & 1.00 \\
\hline & Code-switching & -.20 & .27 \\
\hline & Nonlinguistic Signals & .28 & .12 \\
\hline & Appeal for Help & .24 & .19 \\
\hline \multirow[t]{5}{*}{ Deduction } & Circumlocution & .58 & .08 \\
\hline & Approximation & .03 & .85 \\
\hline & Code-switching & .24 & .19 \\
\hline & Nonlinguistic Signals & $.40^{*}$ & .02 \\
\hline & Appeal for Help & .08 & .67 \\
\hline \multirow[t]{5}{*}{ Interpretation } & Circumlocution & .14 & .45 \\
\hline & Approximation & -.10 & .59 \\
\hline & Code-switching & .12 & .49 \\
\hline & Nonlinguistic Signals & -.01 & .95 \\
\hline & Appeal for Help & -.06 & .72 \\
\hline \multirow[t]{5}{*}{ Evaluation of Arguments } & Circumlocution & -.11 & .55 \\
\hline & Approximation & -.01 & .92 \\
\hline & Code-switching & -.00 & .97 \\
\hline & Nonlinguistic signals & .39 & .03 \\
\hline & Appeal for help & .04 & .81 \\
\hline
\end{tabular}

${ }^{\star}$ Correlation is significant at the .05 level (2-tailed).

\section{Discussion}

The main purpose of this study was to examine the relationship between CT and the preferred type of compensatory strategies among intermediate and upper-intermediate EFL learners.

Before considering the relation between CT and compensatory strategies, the role of gender in CT ability was probed. The findings of this study opposed to the findings of the study ran by Aliakbari and Sadeghdaghighi (2009). In their study, they found that males are better critical thinkers. In fact, there is not a constant and fixed claim about males' outperformance in CT. Regarding the role of gender, the first hypothesis fails to be rejected:

- $\mathrm{H}_{01}$ : There is no significant difference between L2 learners' gender and their CT ability.

According to the descriptive statistics, the priority of compensatory strategies among each group of participants was calculated, and it revealed that the high and mid critical-thinking groups prioritized "code-switching strategy" and the low critical-thinking group prioritized "appeal for help" as their first strategy. As far as the participants were intermediate and upper-intermediate EFL learners, they were supposed not to prioritize code-switching as it is known as an L1-based strategy. According to ČurkovićKalebić (2007), L1-based strategies are commonly used by lower levels of proficiency.

Also, Bialystock (1990) believed that higher levels of proficiency would lead to significantly fewer L1-based strategies. Interestingly, she found that adult L2 learners varied their strategies more freely and they showed more flexibility in terms of compensatory strategy use. Moreover, she claimed that the best strategy users were those who had adequate proficiency in L2, and take advantage of various compensatory strategies. In her idea, good strategy users modified their strategies based on the nature of the concept. 
Therefore, the findings of this study can be justified in this way that prioritizing code-switching by the high and mid critical-thinking groups can be due to the nature of questions. It can be deduced that the high and mid critical thinkers are more aware of the communicative situation than the low critical-thinking group. Moreover, they were more flexible to adopt different strategies based on the communicative purpose.

Regarding the results of the correlation between overall CT ability and the compensatory strategies, a significant positive correlation was observed between the mid-CT group scores and "appeal for help" as a compensatory strategy $(r$ $=.34, p<.05)$. Besides, a significant positive correlation between the low critical-thinking group scores and nonlinguistic signals was found. So far, the second null hypothesis of this study is rejected:

- $\mathrm{H}_{02}$ : There is no significant correlation between CT and the type of compensatory strategies among L2 learners.

As it was mentioned in before, CT and problem-solving ability are closely related to each other, and it is believed that people with higher level of CT enjoy problem-solving ability more. Based on the close correlation between CT and problem-solving, it was supposed that the mid critical-thinking group would avoid "code-switching" and "appeal for help" strategies. According to Poulisse (1990), "code-switching" and "appeal for help" require less problem-solving with little effort. Interestingly, Bou-Franch (1994) conducted a research on compensatory strategies among Spanish learners of English, and he found that the fact that both nonnative speakers share the same L1 increases the occurrence of "codeswitching" and "appeal for help." The same was true for the present study. The participants in this study were asked to take it into account that while answering the questionnaires they were supposed to be communicating with their friends in English under the surveillance of their teacher who shares the same L1. Therefore, the results can be in line with BouFranch (1994) findings.

To make sure about the statistically significant difference in participants' preference of compensatory strategies, the results of chi-square tests can be helpful. As noted before, among all the compensatory strategies only "appeal for help" among the mid CT group was discovered to be significantly different. Considering the fact that the nature of the communicative message may affect the choice of compensatory strategies, it could also be due to the fact that "appeal for help" is a quick and easy way to find the way out. That is why, mid critical-thinking group who formed the largest group prefers it to be applied. Therefore, the third null hypothesis of this study is also rejected:

- $\mathrm{H}_{03}$ : There is no significant difference in preference of compensatory strategies among intermediate and upper-intermediate L2 learners.

As noted in Wohlpart (2007), evaluation of arguments consists of awareness of points of view, purpose, and audience. Also, it is closely related to deduction ability. Therefore, it can be deduced that the higher ability of deduction and evaluation of arguments can lead to the same use of strategies. The findings of this research are also in line with his findings. Actually, a positive significant correlation was found between both deduction and evaluation of arguments with nonlinguistic signals.

As far as one of the concepts of evaluation of arguments is awareness of audience, it could be said that because the participants were told to answer the questionnaires as if they were communicating with their friends. So, the participants with higher ability in evaluation of arguments utilized nonlinguistic signals more, because they were aware of the positive atmosphere between their friends as audience. Therefore, the fourth null hypothesis of this study is also rejected:

- $\mathrm{H}_{04}$ : There is no significant relationship between subcategories of CT and each compensatory strategy among intermediate and upper-intermediate L2 learners.

\section{Implications of the Study}

The findings of this study may help L2 teachers to have a better and realistic view towards L2 learners' choice of compensatory strategies. Besides, the results may also help $\mathrm{L} 2$ learners to have more awareness of compensatory strategies and their own CT. Therefore, the awareness can lead them to effective L2 education.

According to the findings, it seems quite appropriate that $L 2$ teachers evaluate their L2 learners' CT to anticipate and evaluate their performance in a much better way. Actually, taking the CT level of L2 learners into account helps L2 teachers to adjust their expectations. The findings may also help $\mathrm{L} 2$ teachers to have better awareness of the possible variety of compensatory strategies adopted by L2 learners in higher level of proficiency.

It is highly recommended that $\mathrm{L} 2$ teachers help their learners to know more about compensatory strategies and make them ready to make their proficiency problems up. Unfortunately, in Iranian EFL learning context, L2 teachers ignore the role of compensatory strategies, and unconsciously they lead their L2 learners to be anxious and disappointed when they come across with deficiency in their communication. In addition, some L2 learners consider that the use of 
compensatory strategies is not native-like. Therefore, they avoid using such strategies and gradually they may get shut off because of their inabilities to compensate their problems while they are communicating. To avoid it, L2 teacher should include compensatory strategies in their own speaking to provide L2 learners with suitable modeling.

\section{References}

Aliakbari, M., \& Sadeghdaghighi, A. (2009). Investigation of the relationship between gender, field of study, and critical thinking: The case of Iranian students. Proceedings of the 16th Conference of Pan-Pacific Association of Applied Linguistics. 301-310.

Barjesteh, H., \& Vaseghi, R. (2012). Critical thinking: A reading strategy in developing English reading comprehension performance. Sheikhbahaee EFL Journal, 1(2), 21-33.

Bialystock, E. (1990). Communication strategies. Oxford: Blackwell.

Bou-Franch, P. (1994). Communication strategies and topic sequences in the conversational discourse of Spanish learners of English. Revista International de Estudios Estiliscosy Culturales, 2(3), 152-162.

Corder, P. (1983). Strategies of communication. In C. Faerch \& G. Kasper (Eds.), Strategies in interlanguage communication (pp. 1519). London: Longman.

ČurkovićKalebić, S. (2007). On the use of compensatory strategies in learner interlanguage. In J. Horvath \& M. Nikolov (Eds.), UPRT: Empirical studies in English applied linguistics (pp. 269-279). Csoport: Lingua Franca

Dewey, J. (1993). How we think: A restatement of the relation of reflective thinking to the educational process. Lexington, MA: D.C. Heath.

Facione, N., \& Facione, P. (1996). Externalizing the critical thinking in knowledge development and critical judgment. Nursing Outlook, 44(3), 129-136.

Faerch, C., \& Kasper, G. (1983). Plans and strategies in language communication. In C. Faerch \& Kasper (Eds.), Strategies in interlanguage communication (pp. 20-60). London: Longman.

Freely, A. J., \& Steinberg, D. L. (2000). Argumentation and debate: Critical thinking for reasoned decision-making. Stamford: Wadsworth.

Ghanizadeh, A., \& Moafian, M. (2011). Critical thinking and emotional intelligence: Investigating possible relationship among EFL learners and the contribution of age and gender. Iranian Journal of Applied Linguistics, 14(1), 23-48.

Halpern, D. F. (1998). Teaching critical thinking for transfer across domainsdispositions, skills, structure training and metacognitive monitoring. American Psychologist, 53, 449-455.

Kealey, B. T., Holland, J., \& Watson, M. (2005). Preliminary evidence on the association between critical thinking and performance in principles of accounting. Issues in Accounting Education, 20(1), 33-49.

Lynch, T. (1996). Communication in the language classroom. Oxford: Oxford University Press.

Moon, J. (2008). Critical thinking: An exploration of theory and practice. UK: Library of Congress.

Nikoopour, J., Amini Farsani, M., \& Nasiri, M. (2011). On the relationship between critical thinking and learning strategies among Iranian EFL learners. Journal of Technology \& language Education, 5(3), 195-200.

Nour Mohammadi, E., Heidari, F., \& Dehghan Niri, N. (2012). The relationship between critical thinking ability and reading strategies used by Iranian EFL learners. English Language Teaching, 5(10), 192-201.

Oliver, H., \& Utermohlen, R. (1995). An innovative teaching strategy: Using critical thinking to give learners a guide to the future. Retrieved May 4, 2014, from the World Wide Web: www.science direct.com

Paul, R. (1987). Dialogical thinking - critical thought essential to the acquisition of rational knowledge and passions. In J. Baron \& R. Sternberg (Eds.), Teaching thinking skills (pp. 127-148). New York: F. W. Freeman.

Penny Cook, A. (1994). The cultural politics of English as an international language. London: Longman.

Poulisse, N. (1990). The use of compensatory strategies by Dutch learners of English. Dordrecht: Foris.

Tarone, E. (1983). Some thoughts on the notion of communication strategy. In C. Faerch \& Kasper (Eds.), Strategies in interlanguage communication (pp. 129-149). London: Longman.

Wohlpart, J. (2007). Critical thinking: How to read and analyze arguments. London: Longman

Watson, G. B., \& Glaser, E. M. (2002). Watson-Glaser critical thinking appraisal. London: The Psychological Corporation.

Yeh, Y. C. (2004). Nurturing reflective teaching during critical thinking instruction in computer simulation program. Computers and Education, 42(2), 181-194. 